\title{
Imaging Device
}

National Cancer Institute

\section{Source}

National Cancer Institute. Imaging Device. NCl Thesaurus. Code C19747.

A device for producing a representation or picture, usually of a part of the body, to aid in diagnosis and evaluation 